\title{
Endovascular Treatment in the Subclavian Steal Syndrome: Series of 29 Patients
}

\section{Tratamento endovascular na síndrome do roubo da subclávia: Série de 29 pacientes}

\author{
Luana Antunes Maranha Gatto ${ }^{10}$ Diego do Monte Rodrigues Seabra1잉 \\ Gabriel Angelo Garute Zenatti ${ }^{1 \oplus}$ Letícia Frose ${ }^{1 \odot}$ Gelson Luis Koppe ${ }^{1}$ Zeferino Demartini Junior ${ }^{1}$ \\ ${ }^{1}$ Department of Neurosurgery and Interventional Neuroradiology, \\ Hospital Universitário Cajuru, Curitiba, PR, Brazil \\ Address for correspondence Luana Antunes Maranha Gatto, \\ Department of Neurosurgery and Interventional Neuroradiology, \\ Hospital Universitário Cajuru, Rua Sao Jose, 300, Cristo Rei., Curitiba, \\ Arq Bras Neurocir 2021;40(2):e120-e124. \\ Parana, 80050-350, Brazil (e-mail: luanamaranha@yahoo.com.br).
}

Abstract
Keywords
- subclavian steal
syndrome
- arteriography
- left side
- angioplasty
Resumo

Palavras-chave
- síndrome do roubo de
subclávia
- arteriografia
- lado esquerdo
- angioplastia

Subclavian steal syndrome is a group of symptoms resulting from retrograde flow in the vertebral artery, "stealing" blood from the posterior intracranial circulation and other territories, caused by stenosis or occlusion of the subclavian artery proximal to the origin of the same vertebral artery, or even of the brachiocephalic trunk. Most of the time, it is an incidental finding in patients with other conditions or cerebrovascular risk factors. We report a series of 29 patients with an angiographic diagnosis, in which 7 received treatment (all endovascular), all with symptoms directly related to this condition. Advanced age, systemic arterial hypertension, diabetes mellitus, smoking and stroke were comorbidities frequently related. Six patients improved completely after the procedure and one remained with vertigo.

A síndrome do roubo de subclávia é um grupo de sintomas decorrente de fluxo retrógrado na artéria vertebral, "roubando" o sangue da circulação posterior intracraniana e de outros territórios, causado por estenose ou oclusão da artéria subclávia proximal à origem da mesma artéria vertebral, ou mesmo do tronco braquiocefálico. $\mathrm{Na}$ maioria das vezes, trata-se de um achado incidental em pacientes com outras condições ou fatores de risco cerebrovasculares. Relatamos uma série de 29 pacientes com diagnóstico angiográfico, em que 7 receberam o tratamento (todos via endovascular), todos com sintomas diretamente relacionados a essa condição. Idade avançada, hipertensão arterial sistêmica, diabetes mellitus, tabagismo e acidente vascular cerebral foram comorbidades frequentemente relacionadas. Seis pacientes melhoraram totalmente após o procedimento e um permaneceu com vertigens. received

May 19, 2020

accepted

August 24, 2020

published online

February 15, 2021
DOI https://doi.org/ 10.1055/s-0040-1719000 ISSN 0103-5355.

\footnotetext{
(c) 2021. Sociedade Brasileira de Neurocirurgia. All rights reserved. This is an open access article published by Thieme under the terms of the Creative Commons Attribution-NonDerivative-NonCommercial-License, permitting copying and reproduction so long as the original work is given appropriate credit. Contents may not be used for commercial purposes, or adapted, remixed, transformed or built upon. (https://creativecommons.org/ licenses/by-nc-nd/4.0/)

Thieme Revinter Publicações Ltda., Rua do Matoso 170, Rio de Janeiro, RJ, CEP 20270-135, Brazil
} 


\section{Introduction}

Subclavian steal syndrome(SSS) occurs when there is stenosis of the subclavian artery (SA) proximal to the origin of the vertebral artery (VA), causing retrograde flow in the ipsilateral VA. ${ }^{1}$

Most patients are asymptomatic due to the slow progression of the disease and the development of collateral circulation. $^{2}$ The main symptoms of SSS include vertebrobasilar insufficiency and arm lameness. There are reports of cardiac ischemia in patients undergoing myocardial revascularization with mammary artery grafts. ${ }^{3}$ Other possible symptoms include ataxia, tinnitus, syncope, visual disturbances, perioral paresthesia, alternating paresthesia, dysphagia, dysarthria, transient amnesia or headache. ${ }^{4}$

The diagnosis can be made with doppler ultrasound and angiotomography or angioresonance, following the investigation. However, digital subtraction arteriography (DSA) is still the gold standard for its dynamic character. ${ }^{2}$

Optimized drug treatment is the best initial therapy for this syndrome, with surgery reserved for refractory symptomatic cases. Percutaneous angioplasty and stent, in addition to grafts for SA bypass, are the main surgical procedures. ${ }^{5}$

\section{Material and Methods}

A cross-sectional and descriptive study was performed based on the analysis of the series of cases diagnosed in a referral hospital in southern Brazil, between February 2008 and February 2018.

All selected patients were diagnosed by angiography (DSA) and information was collected from the reviews of medical records. Clinical, angiographic and therapeutic characteristics of SSS were individualized and analyzed in each patient.

\section{Results}

The medical records of 38 patients with angiographic diagnosis of SSS between February 2008 and February 2018, performed by the Interventional Neuroradiology team of a public health hospital in southern Brazil, were retrospectively reviewed. Nine were excluded due to poor baseline neurological status related to other causes, considered Rankin modified scale 4 or 5, due to the difficulty in associating SSS with signs and symptoms, and also due to this severe functional disability, there would be no practical benefit of any intervention for the treatment of SSS.

Of the remaining 29, 20 were men (68.9\%) and 9 women (31.1\%). The average age at diagnosis was 66.0 years old (ranging from 45 to 87 years old). In relation to the side of the affected SA, there were 20 cases on the left and 9 on the right. In addition, 22 patients (75.8\%) had significant stenosis or occlusions in at least one more cervical vessel, this being more frequent in males (80\%) than in females (66.6\%). Of the concomitantly affected vessels, the left internal carotid artery (ICA) was the most common ( 16 of 22 patients or $72.7 \%$ of the grand total), followed by the right ICA in 13 patients (59\%), the left VA in 4 (18.8\%), the right VA in 3 (13.6\%), and the basilar artery with 1 patient (4.5\%).
Most had some cerebrovascular risk factor: 20 out of 29 (or $68.9 \%$ ) with hypertension, $58.6 \%$ smoking, $48.2 \%$ previous stroke, $41.3 \%$ dyslipidemia, $34.4 \%$ diabetes, $24.1 \%$ coronary artery disease, $20.6 \%$ peripheral obstructive arterial disease and $6.8 \%$ alcoholism.

Only 9 patients (31.1\%) were symptomatic, and 20 were asymptomatic (68.9\%). The most common symptoms were: syncope (33.3\% or 3 out of 9 ), vertigo (33.9\%) and episodes of low visual acuity (33.3\%), followed by ataxia (22.2\% or 2 out of 9 ) and episodes of mental confusion (11.1\%).

Seven (77.7\%) symptomatic patients underwent stent and balloon angioplasty of the SA. The average time from symptom onset to angioplasty was 15.2 months (ranging from 1 month to 6 years). The procedures were performed through the right femoral access, under general anesthesia and total intravenous heparinization. Normally, a peripheral guide sheath was positioned in the brachiocephalic trunk and a long stent was delivered crossing the stenosis. Although the stent produced partial opening of the vessel, a balloon catheter inflated to 10 to 13 Atm reached a definite impact of the stent and normalized the cervical and intracranial blood flow. There were no complications or related deaths in any of the procedures. In the postoperative period, we maintained the use of simvastatin $40 \mathrm{mg}$ and double anti-aggregation (aspirin 100mg and clopidogrel $75 \mathrm{mg}$ ) daily. Six patients (85.7\%) completely improved their symptoms, and only 1 (14.3\%) maintained vertigo.

The results are shown in - Tables $\mathbf{1}$ and $\mathbf{2}$.

\section{Discussion}

Subclavian steal syndrome is a rare vascular condition, resulting from a subocclusion/ stenosis of the SA or brachiocephalic artery, where blood flows from the contralateral VA to the basilar artery and goes down retrogradely through the ipsilateral VA, leading to collateral circulation in the upper limb. ${ }^{6}$

Contorni $^{1}$ was the first to recognize and describe this retrograde flow, in 1960, using angiography in a patient with an absent radial pulse. A year later, Reivich ${ }^{7}$ associated this phenomenon with transient ischemic attack and, therefore, became the first to correlate it with neurological symptoms. The term "subclavian steal," however, was coined by Fisher ${ }^{6}$ in 1961, after observing that the anomaly caused the ipsilateral SA to receive retrograde flow from the contralateral circulation at the expense of the vertebrobasilar circulation.

The prevalence of SSS in the literature is between $0.6 \%$ and $6.4 \%{ }^{8} \mathrm{~A}$ recent large-scale prevalence analysis found $5.4 \%$ of SSS in a series of 7,881 ultrasound examinations of extracranial vessels in the neck. ${ }^{9}$

Our study indicates a predominance on the left side with 68.9 , and the literature suggests that the left side really is the most affected, reaching $82.3 \%$ in a series. ${ }^{9}$ The justification for predilection for the left side would be the more acute angle of the origin of the left SA, causing turbulence of flow and potential increase of atherogenesis, and consequently, stenosis / subocclusion. ${ }^{5}$

Regarding the prevalence of gender, studies differ mainly in the selection of patients in different studies, with different 
Table 1 Main results of the patients selected in this study

\begin{tabular}{|c|c|c|}
\hline Cases & \multicolumn{2}{|l|}{29} \\
\hline \multicolumn{3}{|l|}{ Gender } \\
\hline & Male & $20(68,9 \%)$ \\
\hline & Female & $9(31.1 \%)$ \\
\hline $\begin{array}{l}\text { Average age } \\
\text { (years old) }\end{array}$ & \multicolumn{2}{|l|}{$66(45-87)$} \\
\hline \multicolumn{3}{|l|}{ SSS Side } \\
\hline & Left & $20(68.9 \%)$ \\
\hline & Right & $9(31.1 \%)$ \\
\hline \multicolumn{3}{|l|}{ Other vessels } \\
\hline & Left ICA & $16(72.7 \%)$ \\
\hline & Right ICA & $13(59 \%)$ \\
\hline & Left VA & $4(18.8 \%)$ \\
\hline & Right VA & $3(13.6 \%)$ \\
\hline & BA & $1(4.5 \%)$ \\
\hline \multicolumn{3}{|l|}{ Risk factors } \\
\hline & Hypertension & $20(68.9 \%)$ \\
\hline & Smoking & $17(58.6 \%)$ \\
\hline & Previus stroke & $14(48.2 \%)$ \\
\hline & Dyslipidemia & $12(41.3 \%)$ \\
\hline & Diabetes & $10(34.4 \%)$ \\
\hline & CAD & $7(24.1 \%)$ \\
\hline & POAD & $6(20.6 \%)$ \\
\hline & Alcoholism & $2(6.8 \%)$ \\
\hline \multicolumn{3}{|l|}{ Symptoms } \\
\hline & Yes & $9(31.1 \%)$ \\
\hline & No & $20(68.9 \%)$ \\
\hline \multicolumn{3}{|l|}{ Main symptoms } \\
\hline & Syncope & $3(33.3 \%)$ \\
\hline & Vertigo & $3(33.3 \%)$ \\
\hline & Loss of Visual Acuity & $3(33.3 \%)$ \\
\hline & Ataxia & $2(22.2 \%)$ \\
\hline & Mental confusion & $1(11.1 \%)$ \\
\hline Treated patients & \multicolumn{2}{|l|}{$7(77.7 \%)$} \\
\hline
\end{tabular}

Abbreviations: BA, basilar artery; CAD, coronary artery disease; ICA, internal carotid artery; POAD, peripheral obstructive artery disease; SSS, subclavian steal syndrome; VA, vertebral artery.

inclusion and exclusion criteria: some analyzing only symptomatic patients, others only treating patients and others all incidental diagnoses by imaging. In the present study, the high prevalence in males was found in a group with an angiographic diagnosis of the imagological subclavian steal phenomenon, not necessarily with the clinical syndrome.

Subclavian steal syndrome is most often caused by atherosclerosis, therefore it is related to cerebrovascular risk factors. ${ }^{10}$ In our series of 29 cases, 26 had at least 1 of these factors. Other etiologies were not found in our series, but include
Table 2 Treated patients in the present study

\begin{tabular}{|l|l|l|l|l|l|}
\hline & Age & $\begin{array}{l}\text { SSS } \\
\text { side }\end{array}$ & Symptoms & $\begin{array}{l}\text { Time } \\
\text { symptoms- } \\
\text { treatment } \\
\text { (months) }\end{array}$ & Results \\
\hline A & 66 & Right & $\begin{array}{l}\text { Vertigo }+ \\
\text { Ataxia }\end{array}$ & 6 & Improved \\
\hline B & 67 & Left & Syncope & 13 & Improved \\
\hline C & 59 & Right & Syncope & 15 & Improved \\
\hline D & 78 & Right & $\begin{array}{l}\text { Syncope }+ \\
\text { LVA }\end{array}$ & 72 & Improved \\
\hline E & 51 & Left & MC + LVA & 1 & Improved \\
\hline F & 81 & Left & Ataxia & 2 & Improved \\
\hline G & 73 & Left & Vertigo & 1 & Maintened \\
\hline
\end{tabular}

Abbreviations: SSS, subclavian steal syndrome; LVA, low visual acuity; MC, mental confusion.

congenital malformations, fibromuscular dysplasia, neurofibromatosis, inflammation (for example, Takayasu and other forms of arteritis), radiation exposure and mechanical causes (for example, trauma or compression syndromes). ${ }^{2}$

Symptoms of vertebrobasilar insufficiency, such as paroxysmal vertigo, dizziness, diplopia, ataxia, dysarthria and syncope, continue to be the main symptoms in the clinical practice. ${ }^{5}$ In the present study, these findings corresponded to $>77.7 \%$ of symptomatic patients, similar to the symptomatic patients treated in the study by Wrotniak et al., with $82 \%$. However, asymptomatic patients still remained the majority, $>70 \%$, according to the literature as being the majority group in the presentation of SSS (which in our study was $68.9 \%)^{9}$

Doppler ultrasound with color flow images (wave amortization or monophasic changes) is the noninvasive modality of choice in the evaluation for subclavian arterial disease. $^{2}$ Angiotomography and angioresonance provide excellent anatomical resolution with accurate information on lesion morphology, length, and location. Invasive DSA is the definitive test, with images not subtracted providing anatomical mapping, while digital subtraction characterizes stenosis. $^{2}$

A small percentage of patients with SSS really need no therapeutic intervention. ${ }^{11}$ Asymptomatic patients should not be submitted to interventions, since they could prevent future disease with medical therapy, which includes antiplatelet drugs, such as aspirin, and a lipid-lowering statin therapy with a goal of low-density protein (LDL) cholesterol $<100 \mathrm{mg} / \mathrm{dL}$. $^{11}$ Stopping smoking, controlling the blood pressure, and glycated hemoglobin A1C rate $<7 \%$ are advised $^{7}$ to reduce the morbidity and mortality risk related to atherosclerotic disease, which can lead to ischemic events in the heart and in the brain. ${ }^{11}$

The surgical vascular intervention options include: axillaryaxillary bypass, carotid-subclavian bypass, and transposition of the SA. ${ }^{12}$ The carotid-subclavian bypass showed low risk of mortality and small recurrence rates. ${ }^{5}$ Law et al. found that 

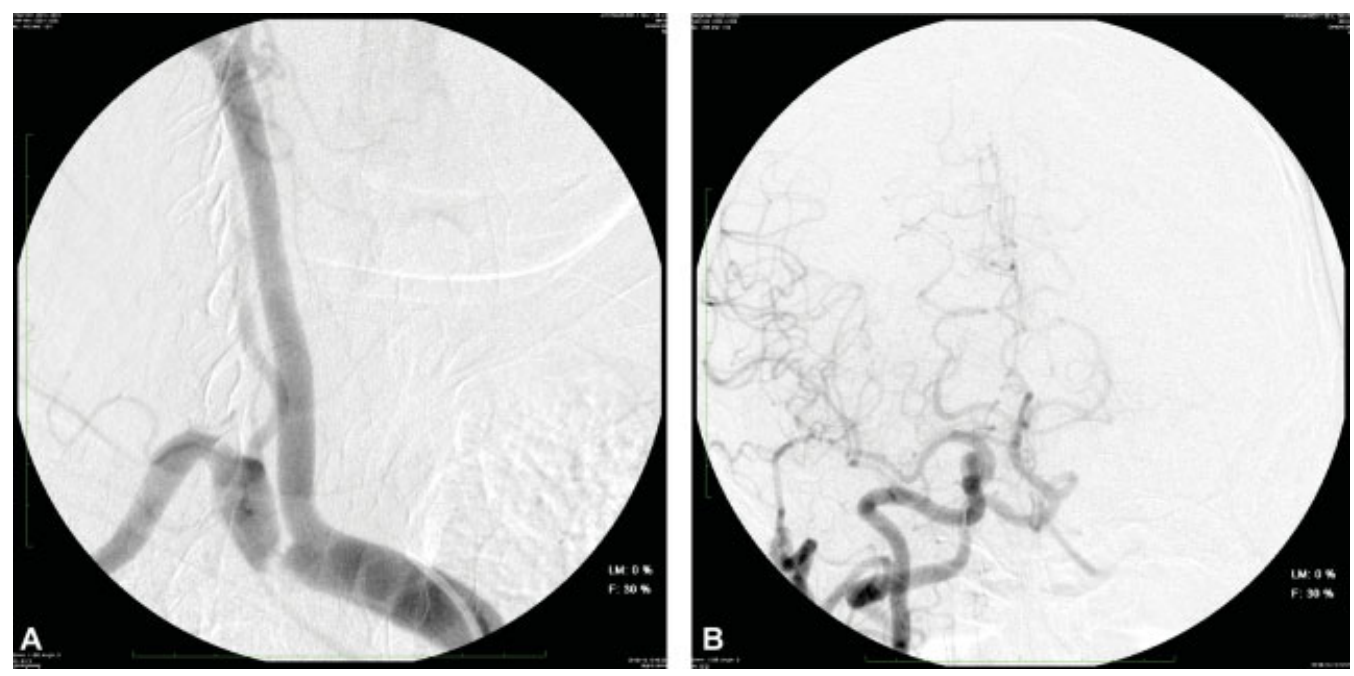

Fig. 1 (A) Right subclavian artery with suboclusive stenosis and a retrograde flow in the vertebral artery. Right anterior oblique view. (B) Right common carotid artery and filling of posterior circulation through extra-intracranial anastomosis. Anteroposterior view.

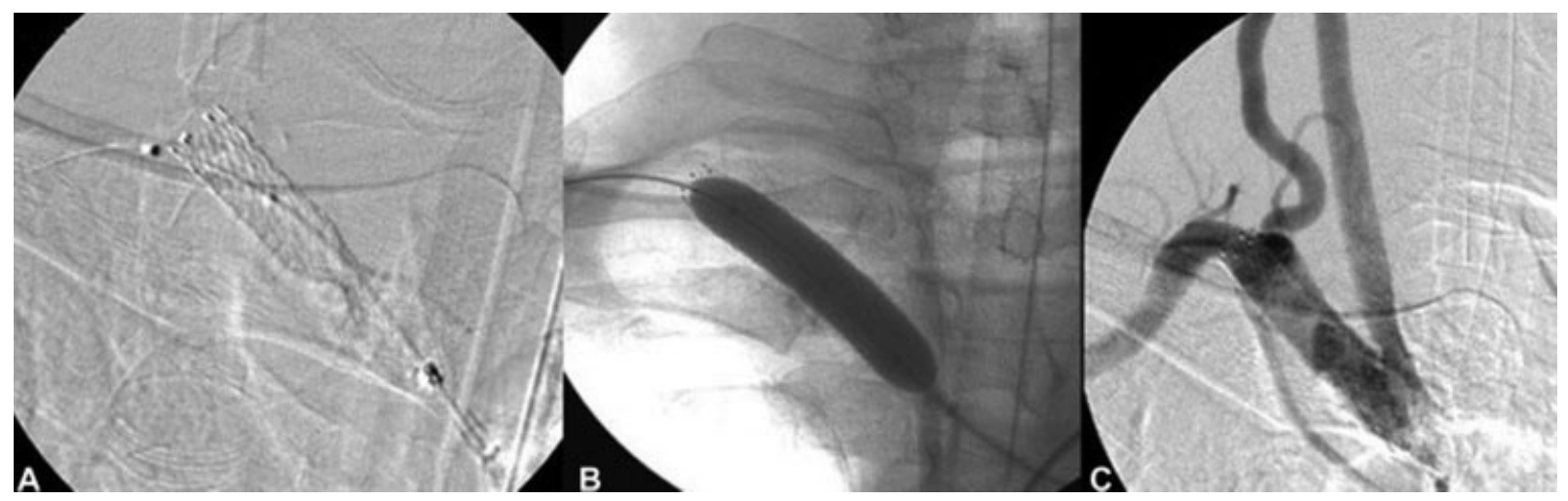

Fig. 2 Angioplasty. (A) Delivered and opened stent covering the entire stenosis. (B) Inflating the balloon. (C) Satisfactory final result.

transpositions have the highest long-term 5-year patency rate (100\%), followed by PTFE (95\%) and Dacron grafts (84\%), and saphenous vein grafts have the lowest patency rate $(65 \%){ }^{17}$ Percutaneous transluminal angioplasty (PTA) has a high rate of patency for subclavian stenosis or occlusion, the latter with a lower rate. ${ }^{13}$ Percutaneous transluminal angioplasty (PTA) has a high rate of patency for subclavian stenosis or occlusion, the latter with a lower rate. Percutaneous transluminal angioplasty has a high rate of good outcome and a low incidence of recurrence, especially in proximal stenosis. ${ }^{14-16}$ It is minimally invasive and, therefore, has lower rates of complications; stenting has been considered safe when compared with the surgical vascular intervention. ${ }^{16}$ In a series of 110 patients treated by PTA with a follow-up of almost 3 years, patients with SA stenosis and occlusion had patency rates of 93 and $65 \%$, respectively. ${ }^{14}$ Risks related to PTA are stroke, arterial rupture, stent migration and reocclusion. ${ }^{16}$ Patients who already had an occlusion presented with a high rate of reocclusion (35-50\%). ${ }^{15,16} \mathrm{~A}$ regular follow-up for at least 2 years post-PTA is recommended. ${ }^{16}$ None of the studies reviewed in the present article clarify how long a patient with total occlusion is still submitted to an intervention with angioplasty (-Figs. 1 and $\mathbf{2}$ ).

\section{Conclusion}

Prospective randomized studies are needed to elucidate the fact that several papers analyze subclavian PTA in stenosis and occlusion, but they do not mention whether or not they have clinical and/or angiographic criteria for SSS.

\section{Conflict of Interests}

The authors have no conflict of interests to declare.

\section{References}

1 Contorni L. [The vertebro-vertebral collateral circulation in obliteration of the subclavian artery at its origin]. Minerva Chir 1960; $15: 268-271$

2 Saha T, Naqvi SY, Ayah OA, McCormick D, Goldberg S. Subclavian Artery Disease: Diagnosis and Therapy. Am J Med 2017;130(04): 409-416

3 Bradaric C, Kuhs K, Groha P, et al. Endovascular therapy for stenoocclusive subclavian and innominate artery disease. Circ J 2015; 79(03):537-543

4 Wrotniak L, Kabłak-Ziembicka A, Rosławiecka A, et al. Resolution of ischemic symptoms after percutaneous angioplasty for a symptomatic subclavian artery stenosis. J Vasc Surg 2016;64(03):684-691 
5 Osiro S, Zurada A, Gielecki J, Shoja MM, Tubbs RS, Loukas M. A review of subclavian steal syndrome with clinical correlation. Med Sci Monit 2012;18(05):RA57-RA63

6 Fisher CM. A new vascular syndrome - "the subclavian steal. N Engl J Med 1961;265:912-913

7 Reivich M, Holling HE, Roberts B, Toole JF. Reversal of blood flow through the vertebral artery and its effect on cerebral circulation. N Engl J Med 1961;265:878-885

8 Karpenko A, Starodubtsev V, Ignatenko P, Gostev A. Endovascular Treatment of the Subclavian Artery Steno-Occlusive Disease. J Stroke Cerebrovasc Dis 2017;26(01):87-93

9 Labropoulos N, Nandivada P, Bekelis K. Prevalence and impact of the subclavian steal syndrome. Ann Surg 2010;252(01):166-170

10 Potter BJ, Pinto DS. Subclavian steal syndrome. Circulation 2014; 129(22):2320-2323

11 Gatto LAM, Chaves JPG, Mendes CH, Seabra DMR, Koppe GL, Demartini Z Jr. Endovascular Treatment in the Subclavian Steal Syndrome - Tratamento endovascular na síndrome do roubo da subclávia. Arq Bras Neurocir 2019;38:137-140

12 Ochoa VM, Yeghiazarians Y. Subclavian artery stenosis: a review for the vascular medicine practitioner. Vasc Med 2011;16(01):29-34
13 Hass WK, Fields WS, North RR, Kircheff II, Chase NE, Bauer RB. Joint study of extracranial arterial occlusion. II. Arteriography, techniques, sites, and complications. JAMA 1968;203(11): 961-968

14 De Vries JP, Jager LC, Van den Berg JC, et al. Durability of percutaneous transluminal angioplasty for obstructive lesions of proximal subclavian artery: long-term results. J Vasc Surg 2005;41(01):19-23

15 English JA, Carell ES, Guidera SA, Tripp HF. Angiographic prevalence and clinical predictors of left subclavian stenosis in patients undergoing diagnostic cardiac catheterization. Catheter Cardiovasc Interv 2001;54(01):8-11

16 Fregni F, Castelo-Branco LEC, Conforto AB, et al. Treatment of subclavian steal syndrome with percutaneous transluminal angioplasty and stenting: case report. Arq Neuropsiquiatr 2003;61 (01):95-99

17 Law MM, Colburn MD, Moore WS, Quiñones-Baldrich WJ, Machleder HI, Gelabert HA. Carotid-subclavian bypass for brachiocephalic occlusive disease. Choice of conduit and long-term follow-up. Stroke 1995;26(09):1565-1571 